\title{
LE PETIT PRINCE Y LA IMAGINACIÓN DE LO INVISIBLE
}

\author{
Álvaro Abellán-García Barrio \\ Universidad Francisco de Vitoria*
}

Resumen

Le Petit Prince ha suscitado reflexiones en diversas disciplinas y su valor teórico ha sido reconocido por importantes filósofos contemporáneos. Este artículo muestra que Saint-Exupéry pretende en esta obra ensayar una «forma de mirar», una gnoseología capaz de recuperar la visión de las realidades invisibles que dan sentido a la vida humana. Justificaremos esta lectura desde la tradición poética aristotélica actualizada en la teoría y metodología hermenéutica de autores como Paul Ricoeur y Alfonso López Quintás.

Palabras clave: hermenéutica, Saint-Exupéry, imaginación, gnoseología, poética.

\section{LE PETIT PRINCE AND THE IMAGINATION OF THE INVISIBLE}

\section{Abstract}

Le Petit Prince has inspired studies in various academic disciplines and its theoretical value has been recognized by important contemporary philosophers. This paper shows that Saint-Exupéry intends in this work to try a "way of seeing», a gnoseology capable of recovering the vision of the invisible realities that give meaning to human life. We will justify this reading from the Aristotelian poetic tradition updated in the theory and hermeneutical methodology of authors such as Paul Ricoeur and Alfonso López Quintás.

Keywords: hermeneutics, Saint-Exupéry, imagination, gnoseology, poetics.

* Este artículo es fruto de mi participación en el Grupo Estable de Investigación «Imaginación y mundos posibles», adscrito a la Facultad de Comunicación de la Universidad Francisco de Vitoria. Agradezco a José María Alejos Bermejo y a Monique Villen sus inestimables aportaciones que han mejorado la calidad de este trabajo. 


\section{INTRODUCCIÓN}

El objeto material de este artículo es Le Petit Prince, un libro con fama de cuento infantil traducido a más de noventa idiomas, entre ellos el quechua, el latín y el griego clásico (Cerisier, 2006: 151-162). Esta pequeña obra ha proporcionado materia de estudio en diversas áreas del conocimiento; por supuesto, en los Estudios Literarios (François, 1957), sobre el uso y alcance del lenguaje (Milligan, 1955) y sobre el uso de los símbolos y las imágenes (Ball, 1981). Pero este relato ha resultado también fecundo en otras disciplinas, como la Antropología filosófica (Caldera, 2013) o la Geografía (Bunkśe, 1990). Alban Cerisier (2006) ha realizado una solvente recopilación y presentación de textos sobre Le Petit Prince, recabando diversos testimonios, entre otros, sobre la valía filosófica de la obra según autores como Martin Heidegger.

En una primera aproximación, puede juzgarse Le Petit Prince como un cuento de hadas moderno o como un relato fantástico. Hay razones para hacerlo, pues los teóricos de lo fantástico han identificado la modernidad del género por su cuestionamiento sobre aquello que consideramos «real» desde la secularización producida durante el siglo de las luces ${ }^{1}$. Según Irène Bessière (2001: 85), el relato fantástico «se corresponde con la formulación estética de los debates intelectuales de un periodo, relativos a la relación del sujeto con lo suprasensible o con lo sensible». Sin duda, el drama del piloto que relata la historia es el de ser víctima de la mentalidad positivista de «las personas mayores»; una mentalidad que agosta su posibilidad para captar las realidades suprasensibles y que trunca su verdadera vocación.

Sin embargo, la literatura fantástica tiene por objeto cuestionar nuestras certezas sobre lo real, poner en crisis nuestra inteligencia: «lejos de perseguir ninguna verdad -explica Bessière (2001: 86)- toma su consistencia de su propia falsedad». Nuestra hipótesis, frente a esta interpretación genérica de la literatura fantástica, es que Le Petit Prince pretende reforzar nuestra inteligencia, capacitándola para adquirir certezas sobre lo eminentemente real. Queremos examinar con rigor el alcance de la

\footnotetext{
${ }^{1}$ Véase, en este sentido, «La importancia del contexto sociocultural» para la aparición del género fantástico (Roas, 2001: 14-24).
} 
frase más recordada del libro: «on ne voit bien qu'avec le cœur. L'essentiel est invisible pour les yeux» (Saint-Exupéry, 1999: 298).

Con frecuencia, acudiremos al pensamiento de Saint-Expupéry expresado en otros lugares, especialmente en sus Carnets-elaborados entre 1935 y 1940; Le Petit Prince fue compuesto a mediados de 1942-. Aunque el propio texto indica al «lector modelo» claves interpretativas ofreciendo el campo de juego de las interpretaciones posibles y de las que no lo son (Eco, 1993: 73), conocer el punto de vista del autor -sobre su uso del lenguaje y su misión como escritor- nos ayudará a identificar el juego estético-gnoseológico que nos propone el texto.

\section{PRESUPUESTOS TEÓRICOS Y METODOLOGÍA}

Todo estudio dedicado a la literatura fantástica implica una oposición, a menudo implícita. Lo fantástico parece destinado a constituir una categoría negativa, proyectada contra lo que se considera normal, natural y objetivo [...] la realidad queda recogida en una entidad por completo accesible y acogedora, fuera de la cual se hallan [...] la irrealidad, la ilusión, la nada (Nandorfy, 2001: 243).

Lo fantástico se define no sólo por romper la lógica de lo normal, natural y objetivo; sino también por el efecto que eso provoca: parecer intelectualmente inaccesible, «inquietante» o, incluso, «terrorífico» (Roas, 2001: 30). La obra de Saint-Exupéry, también Le Petit Prince, se orienta en un sentido distinto: ni pretende violentar o truncar la lógica de lo normal, natural u objetivo, ni pretende, al presentarnos lo superobjetivo o sobrenatural, causarnos desasosiego alguno sino, más bien, lo contrario: reconciliarnos con el mundo.

Saint-Exupéry no combate la lógica ni la verdad de las ciencias positivas, sino que pretende mostrarnos que hay otra lógica para reconocer una verdad mayor. Para Antoine de Saint-Exupéry, «the pursuit of anything but living truth was an indefensible waste of time, and he was not loath to express his contempt of poetic words adorning trite, shalow, or facetious thoughts» (Harris, 1990: 141). Así, su producción literaria es un intento de expresar una «verdad existencial», distinta tanto de las empíricas como de las abstractas. 
La reflexión sobre este tipo de verdad vital es propia de la filosofía existencial, en boga en tiempos de Saint-Exupéry. Según Everett W. Knight (1957: 11), «existentialism seeks to make thought conform to life», por lo que las narraciones literarias son, por excelencia, el lenguaje apropiado para este movimiento filosófico. En ese sentido, Knight entiende que Saint-Exupéry no es sólo un literato, sino un filósofo cuyo pensamiento se expresa literariamente ${ }^{2}$.

Según Bertrand Ball (1981), la escritura era para Saint-Exupéry una forma de acción, de transformación del mundo. Su creación artística está moldeada por su profundo compromiso moral y al servicio de la renovación de la vida, por lo que sus imágenes literarias tratan de sintetizar la vida del hombre en una gran obra de colaboración conjunta capaz de dar sentido a la comunidad humana. Frente a los géneros de «lo fantástico» y de «lo extraño» -por usar la terminología de Todorov (1994)-, Le Petit Prince no pretende provocarnos una incertidumbre paralizante, sino más bien renovar nuestro compromiso moral con nuestra vocación personal y comunitaria.

El lenguaje de Saint-Exupéry «forms an integral part of his attempt to convey to the individual his philosophical beliefs» (Milligan, 1955: 249). Para dotar de un nuevo sentido a las palabras acorde a su visión de lo invisible, el escritor francés emplea, según Milligan, dos dispositivos principales. El primero implica usar la palabra «anagogically; that is, used with a spiritual or moral significance not usually attached to it. This is the opposite of the symbolist's etymological use of words» (Milligan, 1955: 251). Esta apreciación es fundamental para comprender que el uso que Saint-Exupéry hace de los símbolos no está ligado a una búsqueda literaria, estética o erudita, sino moral o espiritual. El segundo dispositivo es la repetición constante, que "whatever its artistic value, has the pedagogical effect of implanting firmly the new meaning of the word» (Milligan, 1955: 251).

Partiendo de los planteamientos del autor cuya obra analizamos, consideramos que una tradición estética y literaria apropiada es aquella que, además de atender con fidelidad a la estructura formal de la obra, convive

\footnotetext{
${ }^{2}$ Knight (1957: 215-246) dedica un capítulo a explicitar las ideas fundamentales del SaintExupéry filósofo. A nuestro juicio, una exposición más ponderada del pensamiento filosófico del autor puede encontrarse en el estudio de Charles Moeller (1978: 142-177).
} 
con naturalidad en el mismo nivel de discurso que la Gnoseología y la Ética, ciencias que se ocupan del conocimiento de la verdad en relación al sentido de la vida. Así ocurre con la tradición hermenéutica inaugurada por Aristóteles tal y como ha sido recibida y actualizada por Paul Ricoeur (1987, 2001) y Alfonso López Quintás (1975, 1998, 2011).

Así, mientras que para buena parte de los teóricos «el texto fantástico subvierte los mecanismos y los presupuestos del texto mimético» (Bozzetto, 2001: 224), nosotros mostraremos que Le Petit Prince es un texto fundamentalmente mimético. Aunque en él se vulneran algunas de las leyes de las ciencias positivas, esto se hace para subrayar, con fuerza poética, la validez de las leyes del desarrollo personal y las claves para el conocimiento de las realidades suprasensibles.

Aristóteles señala que la poética es mímesis de la acción humana; que por mímesis o imitación aprendemos nuestros primeros conocimientos; y que conocer conlleva, por sí mismo, placer. Así, al imitar el devenir de la acción humana -como hace el lector al acompañar al protagonista de un relato- ensayamos imaginativamente posibles cursos de acción que algo nos enseñan sobre nuestras decisiones y sus consecuencias. Nótese que la mímesis aristotélica remite a la lógica de la acción humana y no a las leyes estudiadas por las ciencias naturales, a la que remiten los autores del género fantástico para juzgar los textos fantásticos como no-miméticos ${ }^{3}$.

En este sentido, Aristóteles señala que la poética es más filosófica que la Historia, pues no narra lo que ha sucedido, sino lo que podría o debería suceder según la verosimilitud o la necesidad (Aristóteles, 1974: 157-162). La poética nos proporciona conocimiento sobre lo humano no tanto en el plano histórico, sociológico o científico como en el discernimiento moral, iluminando el sentido de las acciones en orden a la dicha o el infortunio. De ahí que mientras desarrolla estos argumentos, el filósofo insista en que el poeta no es compositor de versos, sino de fábulas (mythos), a partir de diversos elementos que dan explicación de la lógica de la acción humana: lances patéticos, agniciones y peripecias o cambios de la acción en sentido contrario (Aristóteles, 1974: 163). La agnición, el «cambio desde la ignorancia al conocimiento, para amistad o para odio, de los

\footnotetext{
${ }^{3}$ Para una discusión rigurosa, rica y suficientemente actualizada sobre la mímesis aristotélica en relación con sus fundamentos antropológicos y gnoseológicos, véase Schaeffer (1999).
} 
destinados a la dicha o al infortunio» (Aristóteles, 1974: 164), tiene un doble valor de especial significación, es un recurso a un tiempo poético y cognoscitivo. Supone el reconocimiento de que lo que parecía ser de una manera es de otra; hay, ahí, un aprendizaje para el personaje y el espectador.

Los estudios de Ricoeur reunidos en La metáfora viva exploran las posibilidades cognoscitivas de la metáfora apuntadas por Aristóteles y revisadas en un diálogo crítico con la Teoría de la Literatura contemporánea. «La poesía, en sí misma y por sí misma, da a pensar el esbozo de una concepción 'tensional' de la verdad; ésta recapitula todas las formas de 'tensiones' dadas a conocer por la semántica» (Ricoeur, 2001: 414). La más nuclear de todas las tensiones se da en la metáfora. En cuanto que ser "como si», la metáfora sigue sirviéndose de la idea aristotélica de la "adecuación» por lo que, a su modo (analógico, no analítico), dice verdad. Pero su «no ser» mantiene la distancia. En esta tensión se justifica la "pertenencia que incluye al hombre en el discurso y al discurso en el ser» (Ricoeur, 2001: 415). En ese sentido, la experiencia literaria es experiencia del ser mediada por el discurso y la metáfora es un «medio» de participación en el ser que proporciona sentido.

En Tiempo y narración, Ricoeur actualiza las nociones aristotélicas de «mímesis» y de «trama» (mythos) y las contrasta con la Teoría y el Método de la Historia y con la Teoría de la Ficción. Uno de los hallazgos de esta exploración es la noción de «mímesis de mundo». La trama es, para Ricoeur, un «mundo», en cuanto que síntesis coherente y verosímil de elementos heterogéneos, de forma que en ellos se ofrece una totalidad de sentido. La distinción de tres tipos -y momentos- de mímesis le permite vincular la configuración de la trama con la experiencia del mundo compartida por autor y lector; y con la aplicación del lector, en su propia vida, de los aprendizajes existenciales fruto de la comprensión de la obra (Ricoeur, 1987: 120-166). Este proceso remite a aquella afirmación aristotélica de que la poesía enseña lo universal (Ricoeur, 1987: 144).

Alfonso López Quintás (2011: 103) insiste en el «realismo eminente» de cualquier obra literaria de calidad, por cuento significa «un mundo de sentido plenamente real porque funda una serie de ámbitos básicos en la vida del hombre y los engarza conforme a una lógica que a menudo rige la existencia humana». 
Para elevarnos a esa lectura capaz de reconocer la lógica de las realidades invisibles, López Quintás propone algunas claves metodológicofilosóficas, agrupadas en pares de palabras, que nos permiten ser fieles a la literalidad del texto y, a un tiempo, captar su sentido en relación no sólo con la obra, sino con nuestra experiencia del mundo. Nos referimos a los pares hecho-acontecimiento (2011: 32-33), significado-sentido (2011: 33-36) y vértigo-éxtasis o encuentro (2011: 39-43). Para la obra que vamos a tratar, es también relevante el par problema-misterio. «Problema» apunta a la dificultad con la que nos encontramos para resolver algo (por ejemplo, cómo arreglar el motor de un avión). «El 'misterio' no es tanto algo recóndito, incognoscible, cuanto algo 'envolvente' que potencia la capacidad cognoscitiva» (2011: 255) y exige de quien se enfrenta a él no una solución, sino una actitud o un posicionamiento que revela su propio carácter y marca, al menos en parte, su destino (por ejemplo, si tiene sentido luchar por sobreponerse a una situación adversa, como la ruptura del motor de un avión y la caída en el desierto) ${ }^{4}$.

Desde esta tradición hermenéutica, cuyos desarrollos intelectuales coinciden con la intuición de Saint-Exupéry sobre el poder sintético y simbólico del lenguaje literario para revelar las estructuras invisibles de lo humano y su destino, podemos enfrentarnos a Le Petit Prince con una mirada ya algo entrenada.

\section{LA TRAMA DE LE PETIT PRINCE: DOS HISTORIAS DE INICIACIÓN}

Le Petit Prince presenta dos acciones dramáticas completas y entreveradas: la del piloto y la del principito. Ambas guardan un importante paralelismo estructural: situación inicial, carencia, salida del hogar, travesía por el desierto que comporta al menos una difícil prueba, un aprendizaje, algo similar a una muerte y una resurrección, una transformación del personaje y un retorno al hogar. Son, por lo demás, elementos

\footnotetext{
${ }^{4}$ Nótense la casi equivalencia de significado entre los términos aristotélicos y quintasianos: peripecia-acontecimiento, desdicha y vértigo, dicha y éxtasis. Más disímil es la relación entre misterio y agnición, aunque las dos subrayan un momento cognoscitivo relevante y revelador para el destino del personaje. En cualquier caso, la distinción problema-misterio en López Quintás es deudora de los trabajos de Gabriel Marcel (2012). Moeller (1978: 156) subraya el paralelismo que hay entre las nociones problema-misterio de Marcel con las de inteligencia-espíritu que SaintExupéy desarrolla en sus Carnets.
} 
formales bien estudiados durante el pasado siglo (Campbell, 2015; Propp, 2014). Lo interesante, especialmente en una obra cuya lógica altera los presupuestos desde los que solemos mirar la realidad (Campra, 2001: 180), es completar este análisis formal atendiendo al desarrollo dramático que aparece en cada uno de estos momentos, con especial atención a la configuración de la trama.

\subsection{El piloto que quiso ser pintor}

La historia de Le Petit Prince nos es relatada en primera persona. Los datos presentados en el capítulo I concuerdan con la biografía real de Saint-Exupéry. Esta búsqueda de verosimilitud -que nos invita a identificar al narrador o "autor implícito» (Booth, 1983: 431) con el autor realayuda a provocar el asombro propio de los relatos que se deslizan de «lo fantástico» a «lo maravilloso» (Todorov, 1994). Sabemos que Saint-Exupéry escribió este libro en clave autobiográfica, de forma que bajo esta parábola ficcional cabe leer una verdad existencial ${ }^{5}$.

El capítulo I nos introduce en una acción dramática que comporta dos acontecimientos acompañados de agnición. Primero: a la edad de seis años, el narrador lee un libro, descubre su vocación de pintor y realiza su primer dibujo, el de la boa cerrada. Muestra su obra a las personas mayores, quienes no ven lo invisible del dibujo -el elefante- y, al no captar lo invisible, confunden también la superficie -la boa- con otra cosa -un sombrero-. Esta es la segunda peripecia, que conlleva el olvido de su primera agnición y le condena a vivir aislado entre las personas mayores.

El capítulo II comienza con un tercer acontecimiento: el piloto tiene una avería en el motor de su avión y cae en el desierto. Se duerme hasta que al amanecer «une drôle de petite voix» le despertó, espetándole «S'il vous plaît... dessine-moi un mouton!» (Saint-Exupéry, 1999: 237). Que, en la experiencia del piloto, la voz del principito se anticipe a la visión del mismo puede parecer accidental... hasta que constatamos que algo así ocurre otras veces en el libro. En las contadas ocasiones en las que el principito conoce a un personaje que tiene cierta interioridad, conoce de él primero su voz -la serpiente y el zorro- o lo conoce primero bajo otra

\footnotetext{
${ }^{5}$ Que Le Petit Prince es marcadamente autobiográfico resulta evidente no sólo por la configuración de la obra, sino por comparación con la vida real del autor y por el testimonio de sus familiares y amigos, quienes no tienen ninguna duda al respecto (cf. Chevrier, 1958).
} 
forma, antes de revelársele su rostro -la rosa-. Así nos enseña Saint-Exupéry que estos personajes esconden cierto misterio incapaz de ser atrapado o delimitado con la mera visión de los ojos. La configuración dramática de estos encuentros manifiesta una interioridad invisible, misteriosa.

El piloto -«Quand le mystère est trop impressionnant, on n'ose pas désobéir» (Saint-Exupéry, 1999: 238)- dibuja hasta tres corderos rechazados por el principito. A este misterioso personaje sólo le vale el cuarto, uno muy peculiar: "Ça c'est la caisse. Le mouton que tu veux est dedans», dijo el piloto. "C'est tout à fait comme ça que je le voulais!», respondió el principito. ¿Por qué sólo le servía al principito este cordero? La analogía -esta vez visual, entre el dibujo de la boa cerrada y el de la caja- no queda explicada, pero es clara. La voz que clama en el desierto no sólo invita al piloto a "convertir» ${ }^{6}$ su punto de vista, para que recupere de inmediato su verdadera y abandonada vocación de pintor; además, esa voz sabía que el piloto no estaba llamado a ser un pintor cualquiera, sino uno de realidades invisibles -el elefante y el cordero-.

Durante los primeros cuatro días, apenas logra el piloto saber cosas aisladas sobre su compañero. Sólo al quinto (capítulo VII) supo de su rosa y, a partir de ese momento, desde el capítulo VIII hasta el XXIV, cambia el protagonista de la historia ${ }^{7}$. En esos capítulos el relato pasa a la tercera persona: el narrador sigue siendo el piloto, pero el protagonista es el principito. Este recurso literario expresa poéticamente un cambio invisible en el corazón del piloto, quien se despoja de sí mismo para otorgar el protagonismo de su propia biografía al principito. ¿Qué pasó en ese quinto día que justifique tal giro en el relato y tal giro en la relación entre principito y piloto?

${ }^{6}$ El primer pensamiento anotado por Saint-Exupéry en sus Carnets expresa su voluntad por encontrar una forma de mirar, un lenguaje, dentro de cuyo orden el absurdo deje de existir, que sea capaz de conciliar pensamiento científico y valores religiosos en un «langage cohérent» (SaintExupéry 1994: 458 y ss). Considera además que la función de ese lenguaje no es demostrar, sino convertir (Saint-Exupéry, 1999: 538). «Convertir: cette opération lente consiste non à démontrer, ce qui serait fait en cinq minutes, mais à amener à des points de vue tels qu'à leur lumière le monde s'ordonne mieux ou l'homme se sente plus riche» (Saint-Exupéry, 1994: 487).

${ }^{7}$ Este pasaje, y otros del libro, han sido examinados por López Quintás (2011: 229-282) con un propósito distinto: el de explicar la visión de Saint-Exupéry sobre el tema de la amistad. 
Mientras el piloto estaba empeñado en arreglar su avión -le iba la vida en ello-, el principito preguntó si los corderos comen flores. Al piloto le pareció una pregunta absurda. Ese tira y afloja hace estallar al principito:

Il y a des millions d'années que les fleurs fabriquent des épines. Il y a des millions d'années que les moutons mangent quand même les fleurs. Et ce n'est pas sérieux de chercher à comprendre [...] la guerre des moutons et des fleurs? (Saint-Exupéry, 1999: 255).

En este pasaje el principito pasa del plano personal -la preocupación por su rosa- al ontológico -el del misterio de la finitud y la muerte-. Mediante la imagen visible de un cordero que come una flor e inconscientemente aniquila una vida, el principito plantea el misterio de la violencia endémica presente en la naturaleza que obliga a unos seres a aniquilar a otros no por maldad, sino por supervivencia.

El principito llora y el piloto nos confiesa: «J'avais lâché mes outils. Je me moquais bien de mon marteau, de mon boulon, de la soif et de la mort. Il y avait, sur une étoile, une planète, la mienne, la Terre, un petit prince à consoler ! Je le pris dans les bras [...]» (Saint-Exupéry, 1999: 256). El secreto de la vida del principito se le revela al piloto cuando su propia vida le importa menos que consolar a su amigo.

El relato vuelve a la primera persona del piloto cuando estamos ya en el octavo día desde la caída en el desierto. Ya no hay agua, "qu'on va mourir de soif», dice el piloto. "C'est bien d'avoir eu un ami, même si l'on va mourir [...] J'ai soif aussi... cherchons un puits...» responde el principito (Saint-Exupéry, 1999: 302-303). Es absurdo buscar un pozo en el desierto, piensa el piloto, pero inicia la marcha ${ }^{8}$.

Estilísticamente, el equilibrio entre la prosa ordinaria y la simbología de lo invisible invierte a partir de ahora su polo: todos los elementos visibles manifiestan ahora su secreto. Es el capítulo XXIV y será así hasta

${ }^{8}$ La decisión del piloto en este pasaje imita la tomada por Saint-Exupéry cuando cayó en el desierto durante un raid París-Saigón en 1935, según se recoge en el capítulo VII de Tierra de los hombres (Saint-Exupéry, 1994: 237-268). En ambos textos se manifiesta lo absurdo de caminar buscando salvación. En ambos se da un diálogo interior «entre la parte de él que espera y aquella que está convencida de que no hay esperanza, entre aquel que imagina y aquel que razona» (Odaert, 2013: 205-206). Este paralelismo apunta a una especie de elección interior entre una imaginación que pre-ve lo posible, aunque improbable en clave de destino, y una razón calculadora de corte cartesiano, sobre la que hablaremos más adelante. 
el final de la historia. ¿Qué ha ocurrido? Un cambio en la mirada del piloto. Ya había cambiado su actitud, siendo ahora capaz de sacrificar su vida por el amigo (capítulo VII); además, ha conocido la historia del principito y las enseñanzas del zorro. El piloto se pone en marcha y el relato muda de estilo. El pozo que encuentran es típico de aldea, civilización, convivencia, no propio del desierto. Todo lo visible manifiesta ahora su poder invisible, evidenciándose el carácter doble, simbólico, de lo real ${ }^{9}$.

- J'ai soif de cette eau-là, dit le petit prince, donne-moi à boire...

Et je compris ce qu'il avait cherché!

Je soulevai le seau jusqu'à ses lèvres. Il but, les yeux fermés. C'était doux comme une fête. Cette eau était bien autre chose qu'un aliment. Elle était née de la marche sous les étoiles, du chant de la poulie, de l'effort de mes bras. Elle était bonne pour le cœur, comme un cadeau. Lorsque j'étais petit garçon, la lumière de l'arbre de Noël, la musique de la messe de minuit, la douceur des sourires faisaient ainsi tout le rayonnement du cadeau de Noël que je recevais (Saint-Exupéry, 1999: 306-307).

Después de la prueba en el desierto, el piloto arreglará el motor de su avión de inmediato. Rige la misma ley que con el dibujo número 1, ahora en sentido inverso: si no ver lo invisible -el elefante-, impide reconocer lo visible -la boa-, ahora que el piloto se ha enfrentado a lo invisible -la avería en su corazón- logra enfrentarse adecuadamente a lo visible -arreglar el motor de su avión-. Aquí se evidencia, a diferencia de lo que proponen los teóricos de lo fantástico, donde «el choque se produce entre dos órdenes irreconciliables» (Campra, 2001: 159), que hay en Le Petit Prince una integración jerárquica entre lo sensible y lo suprasensible.

La última imagen del libro representa el lugar en el que el principito fue visto por última vez. Es «le plus beau et le plus triste paysage du monde» (Saint-Exupéry, 1999: 321). Una última imagen sensible que remite a una presencia invisible -la del principito- mediante la cual el piloto trata de recuperar el rumbo de su vocación. Junto a esa imagen, una exhortación al lector, una llamada a contemplar ese paisaje aguardando el regreso del principito.

\footnotetext{
${ }^{9}$ Saint-Exupéry (1994: 514): «Il y a la ville visible, il y a la ville invisible. Il y a ce visage que dessinent les chemins campagnards avec leur respect des valeurs spirituelles (les routes desservent le prince)»; «Je ne sais point atteindre d'autre vérité que symbolique».
} 


\subsection{La historia del principito}

Conocemos la historia del principito por boca del piloto, quien nos la cuenta en bloque desde el capítulo VIII al XXIII, a falta del desenlace. Es otra historia iniciática, esta vez en tercera persona, quizá al modo de un moderno cuento de hadas, con al menos una diferencia crucial: al conocerse personalmente el principito y el piloto, se rompen las convenciones típicas del género, según las cuales los cuentos de hadas suceden en un espacio y tiempo que no invaden ni perturban nuestro mundo ordinario (Cf. Caillois, 1970: 10-15). En este caso, el principito invade el mundo del piloto, es decir, nuestro mundo.

El principito habitaba un pequeño planeta del que era señor, pero estaba triste sin saber por qué (situación inicial). Se sentía solo (carencia), hasta que llegó una semilla que germinó en flor. El principito quedó admirado por su hermosura y ella perfumó su planeta entero, habitando el mundo solitario del principito. Esta peripecia afortunada es seguida por otra de signo contrario. La flor era presumida, presuntuosa, complicada. El principito dudó de ella y decidió huir; parte a la aventura visitando los asteroides cercanos al suyo, para buscar una ocupación y para instruirse (Saint-Exupéry, 1999: 262).

La soledad y frustración del principito tocará fondo cuando encuentre un jardín entero de rosas y descubra que su flor no es única. A esta agnición desalentadora le sigue (capítulo XXI) un acontecimiento dichoso, acompañado de la agnición más relevante del relato, arquetipo de las otras: el encuentro con el zorro. «Viens jouer avec moi», le propondrá el principito. El zorro responde que no puede jugar con él, porque no está domesticado (apprivoiser) y le explicará en qué consiste domesticar: «créer des liens» (Saint-Exupéry, 1999: 293-294). Le hablará de la importancia de los ritos y de la paciencia necesaria para la amistad.

El principito se enfrenta de nuevo al jardín de rosas, vuelve con el zorro y este le revela un secreto, que el principito repite, para no olvidarlo. Una repetición significativa, clave para la comprensión de toda la obra:

On ne voit bien qu'avec le cœur. L'essentiel est invisible pour les yeux

[...] C'est le temps que tu as perdu pour ta rose qui fait ta rose si 
importante [...] Tu deviens responsable pour toujours de ce que tu as apprivoisé. (Saint-Exupéry, 1999: 298-300).

Las lecciones del zorro son un destilado de lo que Saint-Exupéry ha descrito con mayor profusión en otras obras. En Terre des hommes, lo hace en un registro ensayístico: la vocación del hombre pasa por su distancia frente a las cosas; distancia que no es física, sino fundada por lazos invisibles con la tierra, la naturaleza, los oficios, el lenguaje y nuestras elecciones personales, que crean una musculatura secreta y viva que imprime orientación y destino a nuestra vida:

Quand nous nous rendons compte de notre rôle, même le plus effacé, alors seulement nous serons heureux. Alors seulement nous pourrons vivre en paix et mourir en paix, car ce qui donne un sens à la vie donne un sens à la mort. (Saint-Exupéry, 1994: 281).

Finalizado su aprendizaje, el principito practicará con otros la mirada que aprendió con el zorro: el guardagujas, el mercader de píldoras que aplacan la sed. Esta vez, como no le ocurrió en su visita a los seis asteroides, reconoce lo que le falta a su interlocutor. La prueba definitiva será la de hacer un nuevo amigo. Es entonces cuando se encuentra con el piloto. El principito, a su manera, logra hacer con el piloto lo el zorro hizo con él. Sólo después podrá volver con su rosa.

\section{UNA PROPUESTA GNOSEOLÓGICA}

En el Capítulo IV de Le Petit Prince se nos habla del astrónomo turco que probó la existencia del asteroide del que provenía el principito. El piloto dirige este episodio especialmente a las personas mayores, pues quiere que su historia sea tomada en serio y sabe que ellas siempre necesitan demostraciones. Sin embargo, el piloto confiesa que le hubiera gustado comenzar su historia de otra manera, más clara para quienes comprenden la vida. Examinemos ambos planteamientos.

Los números y el cálculo nos sitúan en un campo de la Gnoseología relacionado con el método físico-matemático inventado por Galileo que Descartes trató de llevar al campo de la filosofía, al estudio del hombre, el mundo y Dios. Su trabajo fue decisivo para la filosofía europea moderna y, según Saint-Exupéry, impregna la mentalidad de su tiempo. El 
método cartesiano se caracteriza por desconfiar del argumento de autoridad y del testigo; por aceptar sólo lo que se presenta de forma clara y distinta, evidente, al propio entendimiento; y por pensar desde una perspectiva impersonal o neutral, objetiva, diríamos hoy (Fernández Prat, 2002: 17-64). Saint-Exupéry demuestra conocer esto y en otros lugares, como en Carta al general $X$, emite un juicio explícito al respecto:

Les hommes ont fait l'essai des valeurs cartésiennes: hors les sciences de la nature, ça ne leur a guère réussi. Il n'y a qu'un probléme, un seul, redécouvrir qu'il est une vie de l'esprit, plus haute encore que la vie de l'intelligence. La seule qui satisfasse l'homme (Saint-Exupéry, 1999: 330).

Vemos que la mentalidad de las personas mayores es en realidad la mentalidad vigente del hombre europeo moderno. Frente a ella, contrapone el piloto la mentalidad de los niños. En este mismo capítulo IV el piloto confiesa que si no se hubiera sentido obligado a explicarles las cosas a las personas mayores,

J'aurais aimé commencer cette histoire à la façon des contes de fées. J'aurais aimé dire:

«Il était une fois un petit prince qui habitait une planète à peine plus grande que lui, et qui avait besoin d'un ami...»

Pour ceux qui comprennent la vie, ça aurait eu l'air beaucoup plus vrai (Saint-Exupéry, 1999: 246).

Este texto transparenta que Saint-Exupéry es perfectamente consciente de que los cuentos de hadas, en su tiempo, no son tomados en serio. Y, sin embargo, en el manuscrito Lettres à l'inconnue conservado en el Museo de las Letras y Manuscritos de París, Saint-Exupéry dejó escrito: "Sabemos que los cuentos de hadas son la única verdad en la vida ${ }^{10}$. Este texto nos proporciona, todavía, otro elemento para el debate:

Ainsi, si vous leur dites [a las personas mayores]: «La preuve que le petit prince a existé c'est qu'il était ravissant, qu'il riait, et qu'il voulait un mouton.

${ }^{10}$ Contamos con un reciente estudio sobre sobre la filosofía existencial de Saint-Exupéry expresada en su correspondencia personal. También en privado se refleja la preocupación del autor por evidenciar su soledad y su necesidad de vínculos amorosos para dar sentido a la vida (Saiz Cerreda, 2007). 
Quand on veut un mouton, c'est la preuve qu'on existe», elles hausseront les épaules et vous traiteront d'enfant! Mais si vous leur dites: "La planète d'où il venait est l'astéroïde B 612», alors elles seront convaincues, et elles vous laisseront tranquille avec leurs questions (Saint-Exupéry, 1999: 246).

La afirmación "Quand on veut un mouton, c'est la preuve qu'on existe», parece algo forzada, aunque justificada en el contexto de un capítulo que el piloto consagra a demostrarla existencia real del principito, usando los argumentos aceptados por las personas mayores. La frase sugiere una «transtextualidad» que pone este texto «en relación, manifiesta o secreta, con otros textos»(Genette, 1989: 9-10). En concreto, se trata de una alusión al cogito ergo sum de las Meditaciones metafísicas (1641) o al «Je pense, donc je suis» del Discurso del método (1637), el punto de partida de la filosofía cartesiana.

Este capítulo nos propone el acto de querer (frente a la razón solitaria) y el testimonio personal (frente a la demostración científica), como punto de partida para pensar la vida. Estas tesis son próximas a las de otro gran filósofo francés, Blaise Pascal, a quien Saint-Exupéry quiso reivindicar ${ }^{11}$.

Si tomamos en serio estas indicaciones del piloto, junto con los consejos del zorro, ocurre que muchas imágenes y símbolos en Le Petit Prince, más allá del arco dramático, revelan un especial significado, en ocasiones tan velado que permanece oculto a quien no ensaya conscientemente la actitud gnoseológica y la mirada que nos propone el autor. Sin ánimo de ser exhaustivos, está la cuestión de las personas mayores y los niños -una alusión evangélica tan subrayada ( $M t 18,1-5)$ que decidimos expresamente no abordarla aquí-; el que los personajes misteriosos (el principito, la rosa, la serpiente, el zorro) no sean vistos a distancia ni a la primera; la asociación entre los varios dibujos que expresan lo esencial e invisible (el elefante en la boa; el cordero en la caja; la presencia del

${ }^{11}$ Es frecuente, en los Carnets, la preocupación de Saint-Exupéry por lograr nuevas síntesis que superen diversas contradicciones. No sólo entre las ciencias de la naturaleza y los valores religiosos, también entre posiciones políticas, y entre ateos y creyentes. En relación con Descartes -y la ciencia calculadora- y Pascal -y las razones del corazón-, Saint-Exupéry se muestra en sus Carnets más conciliador que el piloto de Le Petit Prince. No obstante, allí entiende que la figura de Descartes está consolidada y que debe recuperarse a Pascal: «L'homme de Pascal (droite) homme de Descartes (gauche). Il reste à écrite la véritable histoire du premier» (Saint-Exupéry, 1994: $577)$. 
principito en la soledad del desierto); la avería en el motor del avión en relación con la avería en el corazón del piloto; la caída en un desierto físico y en un desierto existencial; y los seis primeros asteroides visitados por el principito como símbolos de mundos individuales y solitarios, por culpa, entre otras cosas, de desconocer algunas claves gnoseológicas que dan sentido a la propia vida.

\section{CONCLUSIONES}

La hipótesis que ha atravesado nuestros análisis es la de que, frente a la pretensión habitual de la literatura fantástica, que cuestiona la capacidad de la inteligencia para dar cuenta de la realidad, Le Petit Prince pretende reforzar nuestra inteligencia, capacitándola para adquirir certezas sobre lo eminentemente real. Para probarla, hemos examinado el alcance gnoseológico de la afirmación más conocida del libro: «on ne voit bien qu'avec le cœur. L'essentiel est invisible pour les yeux» (Saint-Exupéry, 1999: 298).

Creemos haber explorado suficientemente el alcance que tiene la afirmación en el mundo ficcional que propone la obra. Primero, en cuando a lo que la acción dramática y la transformación personal del principito y del piloto se refiere. Segundo, en cuando que la obra nos permite entrenar, leyendo sus páginas, esas mismas claves, practicando un modo de leer que enriquece nuestra experiencia personal sobre la vida. Tercero, en cuanto que esas claves son propuestas para mirar el conjunto de la vida humana -externa al mundo ficcional de la obra- mediante recursos que fortalecen la verosimilitud del relato. Cuarto, en los sentidos arriba aludidos, reconocemos que Le Petit Prince es una obra mimética, que toma distancia tanto de los cuentos de hadas como de los relatos fantásticos por su pretensión de fortalecer nuestra inteligencia para el descubrimiento de verdades existenciales capaces de dar sentido a la vida. Pasamos a desarrollar estas conclusiones.

Primero: el repaso al arco dramático del principito y el piloto nos permiten reconocer que ambas historias coinciden en al menos cuatro experiencias dramáticas: a) no es posible una vida plena sin encuentro con el otro; b) el verdadero encuentro con el otro exige reconocer en él su misterio, algo esencial, pero invisible a los ojos; c) aprender a ver lo invisible 
exige crear lazos, invertir tiempo y estar dispuesto a sacrificar la propia vida; y d) la experiencia de encuentro transfigura toda la realidad, haciendo que el mundo visible nos hable, constantemente, del invisible; un mundo más discreto, que no se revela a la primera, pero el único capaz de dar sentido a la vida.

Lo específico de la propuesta gnoseológica del libro pasa por afirmar que las verdades propias del espíritu humano no sólo son asunto de la razón calculadora y el dato empírico, sino que requieren del concurso de otras facultades: a) la actitud -la autocomplacencia frente a capacidad de sacrificio- es determinante para perderse lo esencial o descubrirlo; b) frente a la neutralidad o el desapasionamiento, el compromiso, la responsabilidad y la paciencia son requisitos para captar las verdades invisibles; c) el piloto nos propone una revalorización del conocimiento por testimonio autorizado, frente al razonamiento calculador o la verificación empírica; d) quien no es capaz de penetrar en lo esencial, también fracasa en el conocimiento de la superficie; e) las verdades esenciales no se captan con el órgano de la vista, sino con el de la imaginación, que opera con imágenes, símbolos, analogías y relatos que forman síntesis tensionales capaces de transfigurar nuestra visión de la realidad, dotándola de unidad y articulando nuestra personal relación con el mundo en clave de sentido y destino.

Las experiencias dramáticas del libro respetan la lógica del sentido de la acción humana que exigen Aristóteles y Alfonso López Quintás a las obras literarias de calidad. La gnoseología propuesta y ensayada en la obra para el conocimiento de las realidades suprasensibles también está en consonancia con el método hermenéutico para el conocimiento de las realidades suprasensibles propuesto por autores como Paul Ricoeur y Alfonso López Quintás. Parece razonable pensar que estas experiencias dramáticas y esta propuesta gnoseológica sean parte de la «trama de ámbitos», que se propone como totalidad de sentido en la obra; imagen poética de la creencia de Saint-Exupéry de que «Nous étions gouvernés par la divinité de belles structures permanentes» (Saint-Exupéry, 1994: 626).

Aunque algunas leyes de las ciencias naturales no sean respetadas en Le Petit Prince, sí lo son las leyes del desarrollo personal -en orden a la dicha o infortunio de la persona- y el método para el conocimiento de las realidades misteriosas o profundas; y la forma literaria en la que están 
expresadas esas leyes y este método, las torna más accesibles y evidentes para el lector medio que cuando estas mismas leyes y método son expresados en lenguaje filosófico.

\section{BIBLIOGRAFÍA CITADA}

ARIstóteles (1974): Poética. Trad. V. García Yebra. Madrid, Gredos.

BALL, B. (1981): «Les Images Synthétisées De Saint-Exupéry». CLA Journal, 24.3, págs. 347-351.

BESSIÈRE, I. (2001): «El relato fantástico: forma mixta de caso y adivinación». En Roas (2001: 83-104).

BоотH, W.C. (1983): The Rhetoric of Fiction. Chicago, University of Chicago Press [2 $2^{\mathrm{a}}$ ed.].

Bozzetto, R. (2001): «¿Un discurso de lo fantástico?» En Roas (2001: 223-242). BunKŚE, E.V. (1990): «Saint-Exupéry’s Geography Lesson: Art and Science in the Creation and Cultivation of Landscape Values». Annals of the Association of American Geographers, 80. 1, págs. 96-108.

CAILlois, R. (1970): Imágenes, imágenes... (Sobre los poderes de la imaginación). Trad. D. Sierra y N. Sánchez. Barcelona, Edhasa.

CALDERA, R.T. (2013): La existencia abierta: para lectores de El principito. Madrid, Rialp.

CAMPBell, J. (2015): El héroe de las mil caras: psicoanálisis del mito. Trad. L.J. Hernández y D. Negrete. Ciudad de México, FCE-Joseph Campbell Foundation [2 $2^{\mathrm{a}}$ ed.].

CAMPRA, R. (2001): «Lo fantástico: una isotopía de la transgresión». En Roas (2001: 153-191).

CERISIER, A. (2006): Il était une fois ... Le petit prince. Paris, Gallimard.

ECO, U. (1993): Lector in fabula: la cooperación interpretativa en el texto narrativo. Trad. R. Pochtar. Barcelona, Lumen [3 $3^{\text {a }}$ ed.].

FERNÁNDEZ PRAT, O. (2002): «Introducción». En Descartes, R.: Discurso del método y Meditaciones metafísicas. Barcelona, Tecnos, págs. 17-64.

FrançoIs, C. (1957): L'Esthétique d'Antoine de Saint-Exupéry. Paris, Delachaux \& Niestlé.

GenetTe, G. (1989): Palimpsestos: la literatura en segundo grado. Trad. C. Fernández Prieto. Madrid, Taurus.

HARRIS, J.R. (1990): «The Elusive Act of Faith: Saint-Exupéry's Sacrifice to an Unknown God». Christianity and Literature, 39.2, págs. 141-159. 
KNIGHT, E.W. (1957): Literature Considered as Philosophy: The French Example. London, Routledge and Kegan Paul.

LóPEZ QuiNTÁs, A. (1975): Metodología de lo suprasensible II: el triángulo hermenéutico. Palma de Mallorca, Publicaciones de la Facultad de Filosofía y Letras [2 ${ }^{\mathrm{a}}$ ed.].

- (1998): Estética de la creatividad: juego, arte, literatura. Madrid, Rialp.

- (2011): Literatura francesa del siglo XX: Sartre, Saint-Exupéry, Camus, Anouilh, Beckett. San José (Costa Rica), Promesa.

MARCEL, G. (2012): En camino, ¿hacia qué despertar?: autobiografía. Trad. J. Padilla Moreno. Salamanca, Sígueme.

Milligan, E.E. (1955): «Saint-Exupery and Language». The Modern Language Journal, 39.5, págs. 249-251.

MoELLER, C. (1978): Literatura del siglo XX y cristianismo. V: Amores humanos. F. Sagan, B. Brecht, Saint-Exupèry, S. de Beauvoir, Valèry, Saint-John Perse. Madrid, Gredos [2 ${ }^{\mathrm{a}}$ ed.].

NANDORFY, M.J. (2001): «La literatura fantástica y la representación de la realidad». En Roas (2001: 243-261).

ODAERT, O. (2013): «El mito del principito». En La historia completa de El Principito. Barcelona, Salamandra.

Propp, V. (2014): Morfología del cuento. Trad. F. Díez del Corral. Madrid, Akal [6 $6^{\text {a }}$ reimpr.].

Ricoeur, P. (1987): Tiempo y narración I. Trans. A. Neira. Madrid, Cristiandad. - (2001): La metáfora viva. Trans. A. Neira. Madrid, Cristiandad [2a ed.].

RoAS, D. (ed.) (2001): Teorías de lo fantástico. Madrid, Arco/Libros.

SAINT-EXUPÉRY, A. de. (1994): Euvres complètes I. Ed. M. Autrand y M. Quesnel.

Paris, Gallimard.

- (1999): Euvres complètes II. Ed. M. Autrand. Paris, Gallimard.

SAIZ CERredA, M. del P. (2007): Cartas íntimas de Antoine Saint-Exupéry: entre la soledad y el amor. Pamplona, Ediciones Universidad de Navarra.

SCHAEFFER, J.M. (1999): Pourquoi la fiction? Paris, Seuil.

Todorov, T. (1994): Introducción a la literatura fantástica. Trad. S. Delpy. Ciudad de México, Ediciones Coyoacán.

Álvaro ABELLÁN-GARCÍA BARRIO Universidad Francisco de Vitoria a.abellan.prof@ufv.es 0000-0002-1569-8646 
